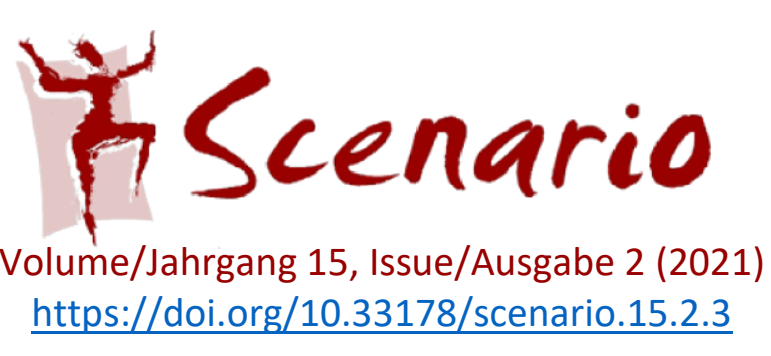

\title{
Drama and critical intercultural language pedagogy
}

Jenna Nilson

This article discusses findings from a research project with emergent bilingual youth in Phoenix, Arizona. This project focused on how critical intercultural language pedagogy impacts how and what methods of performative language teaching drama and language practitioners employ in the English as an Additional Language (EAL) class through engaging aspects of a Youth Participatory Action Research methodology (YPAR) and through taking a Mantle of the Expert approach in a process drama. The article uses Tania Cañas' manifesto "10 things you need to consider if you are an artist not of the refugee and asylum seeker community-looking to work with our community" to situate how this project sought to examine ethical process when working with language minoritized youth in the context of English language learning in the United States. Cañas (2015) argues that artists need to examine how their project methodologies promote equitable exchange, as well as how their participation frameworks situate power. In relation to the above points in Cañas' manifesto, the article discusses findings from the research project, and examines how effectively the project considered equitable exchange and power dynamics within the context of language learning. Findings relate how drama practitioners and language teachers must critically reflect on and focus their students' choice and decision-making throughout the process, as well as seek to meaningfully incorporate students' linguistic capacities in both English and their first languages.

\section{Introduction}

In the summer of 2020, I began a research project with emergent bilingual students, students who are in the process of acquiring English as an Additional Language, in Phoenix, Arizona. I draw from bilingual education scholars Ofelia García and Jo Anne Kleifgen's (2018) use of the term emergent bilingual, a term the scholars argue emphasizes students' bilingualism rather than their "lack of English" (p. xiv). My specific interests stemmed not only from my previous explorations of how performative methods support English language learning, but also from my own language teaching philosophy: English language teaching needs to work from an asset-based model that actively seeks to deconstruct inequities among language minoritized students. Language minoritized students, a term also discussed by García and Kleifgen (2018) in the literature on bilingualism, are students who are in the process of learning the official language of the country in which they reside, for example learning English as an additional language in the United States (p. 3). 
At the Scenario Online Research Colloquium in January 2021, I was introduced to Tania Cañas' manifesto: "10 things you need to consider if you are an artist not of the refugee and asylum seeker community- looking to work with our community." Cañas (2015) proposes a series of points for drama practitioners and artists to consider on how to ethically work and partner with refugee and asylum-seeking populations. Specifically, in point one of her manifesto, Cañas (2015) asserts how artists and practitioners must consider the process of the partnership rather than the final product, examining how power structures either work towards, or against, equitable exchange, and, in point four, Cañas asks artists to consider if participation frameworks are "reinforcing" existing power dynamics. I discuss Cañas' preceding arguments as applied to my project to examine the ethical implications of working with language minoritized youth in the US.

By engaging components of Participatory Action Research (PAR) methodology, my project's inquiry focused on the following question: How does critical intercultural language pedagogy impact performative teaching practice in the EAL class? In PAR, students as researchers decide on what methods and structure they want to use, as well as the topic or issue of the inquiry, to investigate and transform areas of their lives (Camarota \& Fine, 2008, p. 5). In my approach, I used the Mantle of the Expert technique within a process drama to emphasize students as stakeholders in an issue regarding their education and communities that they themselves defined.

Process drama is a method used in drama-based teaching and learning that emphasizes the "active identification with and exploration of fictional roles and situations by the group," thereby giving autonomy to the learners to decide in collaboration with the teacher how the sessions will unfold (Kao \& O'Neill, 1998, p. 12). 'Mantle of the Expert' is an approach to drama-based work in the classroom developed by drama practitioner Dorothy Heathcote where participants become leaders in a fictional scenario where they and the teacher take on the role of 'professionals' to address and reflect upon a topic, often 'solving' a particular problem through an episodic exploration of an imagined dramatic world (Heathcote \& Bolton, 1995). Mantle of the Expert (or as I refer to later as 'mantle') has since been widely used in different international contexts. Mantle can be a drama convention, or a technique, where students must complete a task in role as a "specialist" on a topic such as a scientist or historian, whereas in other places, such as in the New Zealand curriculum, Mantle is an "approach to inquiry" where students work in role as members of a company for a client (Heathcote \& Bolton, 1995; How can MoE be used?, n.d.; Mantle of the expert, n.d.; Neelands \& Goode, 2000). However, whether technique, approach, or convention, or whether students are members of a company or scientific researchers, Mantle of the Expert positions students as the knowledge-holders in the classroom with a specific, real-life task to accomplish. 
In my project, I define and use Mantle of the Expert as a technique within an overall performative approach to language teaching that where students, in roles as experts on a particular topic within a fictional scenario, must work together to create a tangible report, pitch, project, or proposal as their expert characters might do in real-life. I decided to use Mantle of the Expert to highlight emergent bilingual students' linguistic and cultural knowledge in the classroom space and to de-center the teacher as the sole decision maker. Mantle of the Expert is a radical shift from the teacher-centered pedagogical practices that permeate the US educational system, in particular in English language learning (García \& Kleifgen, 2018; Shin, 2018). Using Mantle of the Expert influenced the other dramatic techniques that I used throughout the process, as I worked to build towards the students drawing from their own experiences and knowledge to fulfill their role as experts in their chosen topic. For example, I asked students to tell a story about a time that they overcame a challenge to prepare them for their characters as experts who solve a problem in the drama. I, thus, focused on Mantle of the Expert as the driving technique behind the drama as a way to challenge the power dynamics of a traditional English language class. Within a dramatic scenario decided on by the students and using the Mantle technique, I hoped for participants to share their unique and real-life expertise as bilingual youth with diverse cultural experiences.

However, while I selected a research framework that attempted to provide students with a choice on how the project would unfold, my efforts surrounding the incorporation of students' first languages and own decision-making in the research showed the ethical flaws in my process. The preceding observation reflects Cañas' (2015) statement in her manifesto that just because a project takes a particular methodology, it does not mean that all exchanges in the process are equal or beneficial to both partners. I found that although the Mantle of the Expert technique in process drama opens the space for sharing cultural perspectives, and encourages communication in the target language, I still needed to ensure all students felt their home languages and cultures respected and valued in the space. Moreover, while I attempted to shift the teacher-student power dynamic in the classroom by including students as decisionmakers in the drama, I did not fully incorporate their perspectives into the drama nor research process as a whole, relating to Cañas' point that artists must examine how participation frameworks may indeed reinforce the very power dynamics they are aiming to subvert. From my reflections on the ethical challenges of my own work in the context of Cañas' above assertions in her manifesto, I offer two key considerations for drama practitioners and language teachers working with language minoritized populations. 


\section{Research background: Critical intercultural language learning in the performative language class}

Through kinesthetic social interaction, reflection and analysis, drama-based work highlights both the physical and reflective aspects of the intercultural language classroom. In their conceptualization of intercultural language learning, Liddicoat and Scarino (2013) emphasize the importance of creating opportunities for meaningful social exchanges within the language classroom and situate intercultural learning as an "embodied process" (p. 51). Liddicoat and Scarino's (2013) argument supports the interactive nature of intercultural language learning. Thus, drama is an effective vehicle through which to introduce active meaning-making through embodiment in intercultural language teaching. Process drama emerges as a useful approach through which to activate students' cognitive awareness and analysis because the learning derives from student-led explorations of a cultural topic or theme (Piazzoli, 2018 Rothwell, 2011; Salopento, 2008). The preceding examples help to provide solid frameworks that I consider in the context of my work: process drama, through embodiment, opens opportunities for reflection and analysis on the differing perspectives of students, particularly those from diverse cultural backgrounds.

However, intercultural language teaching does not always occur in spaces where we study and compare cultures outside of our own, for example, in a French as a Foreign Language class in the US where students learn about the language and culture of French speaking countries, nor in societies where all languages and cultures are equally valued. As intercultural teachers and practitioners, we must always consider the context in which we teach. In my consideration of the cultural and social contexts of language teaching in the US, I assert that performative intercultural language pedagogy must ultimately be informed by a critical approach when working with emergent bilingual students. Intercultural language pedagogy can idealize 'harmonious diversity' rather than critically examine the lived experiences of language minoritized students who must navigate inequitable power constructs created by the dominant language group (Frimberger, 2017, pp. 50-51). The preceding point ties back to Cañas' (2015) argument that artists must carefully question their process and participation frameworks to avoid further perpetuating inequitable power dynamics and the exploitation of marginalized populations.

I believe in creating educational environments where all students thrive. As a white educator in the US, I must be constantly aware of how power structures operate in my classrooms to avoid deficit-based views that suppress language minoritized students. My research, thus, builds from pedagogies that seek to disrupt and dismantle deficit-based ideologies. I draw from the work of critical education theorists and scholars who argue that when engaging in 
intercultural learning with marginalized populations, students should be provided opportunities to express their immediate cultural and linguistic knowledge, and they need a curriculum that challenges them to solve issues together through collaborative inquiry (Cummins, 2000; García \& Kleifgen, 2018; Paris \& Alim, 2014). The argument for creative, collaborative, challenging, and culturally sustaining curricula carves a unique place for performative language teaching methods, and, more specifically, for the use of process drama as a method that positions students as directors in their own learning.

\section{An inquiry-oriented approach}

After examining the literature related to past studies on drama and intercultural pedagogy, as well as critical education theory, I determined that the field of drama education can benefit from further collaborative inquiry practices to explore intercultural language learning. The term 'research' itself can thus be problematic when working with language minoritized communities who have been studied as subjects, rather than acknowledged and included into the study as participants with their own voice and agency (Phipps, 2013, pp. 1-10). Youth Participatory Action Research (YPAR) is a research approach that actively seeks to include all participants in the process, shifting from methods that study upon, to a framework that studies 'with' the participants. YPAR reflects Cañas' emphasis on questioning the power structures in the process of participatory projects with marginalized populations. In working towards ethical research practices with language minoritized youth, I sought to use aspects of the YPAR framework to consciously include my participants' perspectives in an inquiry-based project design.

As explored above, literature on performative pedagogy and intercultural language learning suggests that drama can be a powerful medium to explore perspective-taking and embodiment when reflecting on one's own ideology and culture, and that of people in other cultures and countries. However, the field of performative language teaching can further explore drama-based pedagogy in relation to the intercultural language classroom when working with language minoritized and marginalized youth affected by systemic educational inequities. My research ties together both the literature on critical education theory and performative pedagogy when working with English learners through the Mantle of the Expert technique in a process drama.

\section{Methodology}

I used aspects of the Youth Participatory Action Research (YPAR) methodology, employing focus groups, end of project questionnaires, video recordings of each session, and teacher- 
journaling as my research methods. I included key tenets of YPAR, focusing on the participants' knowledge, collaborating with participants to decide on a central theme to drive the inquiry of the drama, and challenging existing educational power structures, deconstructing the deficit-based model of English language teaching by providing students' instruction and support in their first languages. However, I acknowledge that my research does differ from existing YPAR projects as I chose the methods for investigation. The analysis covers the limitations this posed in the extent to which I addressed participation and decision-making by my participants in the process.

\section{Data collection and analysis}

At each of my partnering research sites, Valencia Newcomer School and Choice Learning Academy, I led five ninety-minute workshops hosted virtually over the schools' online learning platform, Webex. With each of the groups, we started by exploring what students might want to choose as a topic for the "Future Of...?" process drama through reflecting on the following questions about their schools and communities: "What do you like about your school/community? What do you want to do more of at school? What do you want there to be at school/in your community in the future?". The Choice Learning group decided on the topic of "The Future of Sports Club Programs," as participants said that they wanted to have more clubs at school and areas to play sports. At Valencia, we narrowed down the topic to "The Future of Music and Dance," as many of the students said that they wanted more opportunities for arts classes at school, and they expressed an interest in music and/or dance classes. With the Choice Learning group, I then facilitated initial explorations into who the participants' characters as experts might be in the drama by first discussing options for different professionals in the field of sports (i.e., sports players, sports coaches, etc.), and then 'interviewing' these professionals about how they manage challenges in their careers. Once both participants, Sofia and Natsu (pseudonyms), decided on their characters as professional sports coaches, I came up with the dramatic scenario of inviting the students as their coach characters to create a proposal for a new youth sports club program for the City of Phoenix Parks and Recreation Department. Sofia and Natsu developed their proposal in character and then presented their proposal to an invited council member from the City of Phoenix Parks and Recreation department, during the last session. After deciding on the topic with the Valencia group, we also talked about who different professionals in music and dance might be. However, because I progressed more slowly with the Valencia group and because of the challenges I faced with the groups' varied first languages and English levels, we did not delve deeply into character work. Instead, I created the dramatic scenario where students were 
invited to participate as dance experts in a dance-off where they chose teams to create and present "The Best New Dance of 2021".

During the last fifteen minutes of the session, I led a focus group with the participants to reflect on and receive feedback on the session, and this was also recorded via Webex. To offer participants a variety of communicative forms, I gave participants the option to either answer verbally or write their answers in the Webex chat feature, and answer verbally and/or write in their first language. The focus group consisted of four open-ended questions aimed at gathering participants' reflections on their own learning and feelings about the session. I also incorporated one aesthetic reflection response in each of the focus groups. Rather than drawing on speaking or writing, the multimodal reflection allowed the participants to respond creatively using their bodies and/or imaginations. These included: responding to the questions with the title of a song, responding to the question with a photo, or responding to the question with a movement. Immediately after each workshop, I reflected on the session in my teacherjournal, responding to the following questions: What were moments of participants' physical, verbal, and emotional engagement? What were moments of disengagement? Did participants engage in spontaneous communication in English? Were there any moments when participants used their first language to engage in the session? In the final workshop session, I asked each of the participants to fill out an open-ended questionnaire sent via a shared Google Survey that could be completed in English or in their first language. I analyzed the data gathered from the video-recordings, journal, questionnaires, and focus groups using coding strategies to identify themes among learners' verbal, physical, and emotional responses to the sessions. As a teacher-researcher, I facilitated the sessions, led the focus groups, and conducted the data analysis, although I did confer with my committee members on sections of my video analysis.

I used Johnny Saldaña's (2011) Fundamentals of Qualitative Research and The Coding Manual for Qualitative Researchers to guide my coding process. I started by first-cycle coding each participant's focus group responses and end-of-project surveys using In-Vivo and Values coding methods, and my teacher journal using In-Vivo methods. I chose to use In-Vivo coding because I wanted to highlight my participants' reflections and voices in the data analysis process, and to situate my immediate thoughts/reflections from my teacher-journal in conversation with my participants. As Saldaña notes in regards to In-Vivo coding, "the child and adolescent voices are often marginalized, and coding with their actual words enhances and deepens an adult's understanding of their cultures and worldviews" (p. 106). In-Vivo coding, thus, aligns with the core values of a participant-centered approach in YPAR, and proves useful when working to focus the perspectives of emergent bilingual students. I also chose to use Values coding for the focus-group sessions as I wanted to further highlight my 
participants "perspectives or worldview(s)" (Saldaña, 2011, p. 131). Notably, Saldaña discusses how Values coding can be applied to studies that "explore cultural values and belief systems," which I examine within this project (p. 132). Once I had all the video recordings, I completed a video analysis of each session drawing from Saldaña's description of how to analyze live and recorded action (pp. 62-64). I broke down the session into time segments according to activity, and then wrote a description and analysis of what occurred during that activity. As I was coding and completing my video analysis, I also used analytic memos to note themes, categories, patterns, ethical concerns/dilemmas, person connections, problems, future directions, and any other notable moments and aspects of the study that came up for me in the data collection and analysis process.

\section{Participants}

I recruited a group of emergent bilingual students in sixth through eighth grade programs at Valencia Newcomer School and Choice Learning Academy, both located within the Alhambra School district in Phoenix, Arizona. I identified Valencia Newcomer School and Choice Learning Academy as potential partner sites as these schools have a high population of new arrivals who are in their first or second year of living in the US, and/or students in the process of acquiring English as an Additional Language. Overall, the Alhambra School District demographics show eighty percent Hispanic students and about a quarter of students as English Language Learners (ELLS) (Alhambra elementary district, n.d.). Almost ninety percent of students come from low-income families (Alhambra elementary district, n.d.).

\section{Statement of positionality}

I include a statement of my relationship to language learning to situate how my own identity impacts not only my research, but also how my background positions me in relationship to my participants. I now consider myself bilingual in English and Spanish, though I grew up in an English-speaking monolingual household. I draw from bilingual education scholar Sarah Shin's (2018) definition of 'bilingual' as someone who can use two languages "to the extent required by his or her needs and those of the environment" (p. 7). I started to learn Spanish in high school, and I continued to practice when I moved to Madrid, Spain after graduating from college. However, my experience with language learning differs greatly from my project participants, as well as the majority of bilingual students in the US. My position as a white, native English speaker who then acquired Spanish as a second language situates me within the constructed dominant language community in the US. My experience as a bilingual living in a foreign country where I did not speak the national language differs greatly from the experience of language minoritized students living in the US and Canada. I acknowledge the 
sociocultural, economic, and political factors that impact language minoritized students, and the discriminatory policies and practices that affect bilingual communities (García \& Kleifgen, 2018). I, thus, am conscious of my privilege, and the potential misperceptions I may hold of the experience of being bilingual.

\section{Findings}

Overall, I found that the Mantle of the Expert technique in process drama can encourage sharing of cultural and linguistic perspectives, and foster communication in the target language when students are provided with appropriate linguistic resources to effectively complete the task. However, within my aim to offer students the option to express themselves in their first languages during the data collection process, I struggled to ensure that all participants were equally supported in this regard. And, in my goals to create a space that positioned students as decision-makers in the inquiry through drama, I overlooked where I, as the teacher, was asserting my authority and agenda in the process. I turn first to first language accessibility, then I examine the performative methods and participation frameworks. Finally, I reflect on my project through the lens of Cañas' arguments regarding equitable exchange and power dynamics.

\section{First language accessibility}

I concluded from my data-analysis of the focus groups, end of project surveys, and teacher research journals that the accessibility of the students' first language during the sessions affected both participant emotions and enjoyment as well as language attitudes. With the Choice Learning group, both participants had the same first language, Spanish. Thus, I could also communicate in Spanish during the sessions, and I reiterated throughout the workshops that Sofia and Natsu could feel free to use Spanish as needed. While neither Sofia nor Natsu used Spanish during the focus groups or in the end of project surveys, there were several instances where Sofia asked if she could express herself using Spanish or if I could clarify in Spanish instead of English.

At Valencia, students did not have a common first language. Although the school had a Swahili translator, he was only able to attend some of the sessions. For the Spanish-speaking students, either the first faculty host who spoke Spanish, or I provided clarification during parts of the workshop. However, students who spoke other languages did not receive the same explanations when the Swahili translator could not be present. Overall, the language support was not consistent. From my reflections in my teacher-journal, I observed very few to no instances of participants using their first language. Only one participant, Sabrina (pseudonym), wrote some of her responses in Swahili in her end of project survey. 
In the end of project survey, Sofia and Natsu responded positively to the question "Did you feel that your home/first language was valued and respected?" Sofia said that "Yes, because now I can speak two languages, English and Spanish," and Natsu expressed that "I felt great." I only received one completed survey at Valencia from Sabrina, who reported that she did not know if her first language was valued or not during the sessions. She did communicate positive feelings towards speaking English in her answer to the question "How do you feel about speaking English after completing this program?" saying that "I really feel so good." However, she also noted that "I still don't understand English very well."

Sofia and Natsu's responses from the end of project survey and my data from my teacherjournal and video analysis suggest that I had developed a space where participants felt comfortable using their first language when needed, and that their home language was valued. At Valencia, while Sabrina enjoyed practicing English, she communicated an uncertainty towards understanding English and whether or not her home language was valued, revealing that I did not foster a space where she felt her first language respected and included in the process. In critical intercultural language education, we need to pay attention to how we provide opportunities for students to use their full linguistic repertoire, particularly when working with groups of students with a diversity of language backgrounds. Although I told participants that they could write or speak in their first languages during the focus groups, this was not sufficient to guarantee that participants felt their home languages valued and respected. I needed to ensure that the students would all be equally heard and understood during the workshops if they chose to use their first language, and that I provided equal linguistic support in their home languages. Language and drama educators can effectively apply their own language knowledge or work to learn words and phrases in their students' first languages to foster mutual understanding and respect, valuing the "linguistic practices" that culturally sustaining pedagogies seek to include (García \& Kleifgen, 2018, p. 112).

\section{Performative methods and participation frameworks}

How successfully did a performative method to language teaching, specifically the use of Mantle of the Expert, encourage communication, sharing of students' own cultural and linguistic perspectives, and learner expression of agency and decision-making? With the Choice Learning group, I started the first session by having Sofia and Natsu share which languages they speak and where they were from. My data suggests that beginning by talking about our language backgrounds and where we were from planted the seed for a willingness to share and participate that emerged throughout the subsequent sessions. During the second session, we played a warm-up game called "Where I Am From," where we shared statements 
about the geography, culture, and values of where we lived or had lived in the past. Sofia commented in the focus group after this session that "what I learn is more about Each [sic] other cultural and communication." Furthermore, I used a few short story-sharing prompts as warm-up exercises. In one of the prompts, I asked participants to reflect upon their favorite food. Here, Sofia went into detail describing her favorite food from Guatemala, a type of Guatemalan chow-mein. These short get-to-know-you activities were also effective in opening the space for participants to discuss their unique cultural backgrounds.

In addition to the previous ensemble-building techniques, the process drama and Mantle encouraged participants to share their perspectives through working together as characters to problem-solve. Both Sofia and Natsu made specific choices as their coach characters and interacted verbally throughout, showing their commitment to the drama and willingness to communicate in the target language. When I asked after one session "What was it like to use your body, voice, and imagination in English?", Nastu responded that "It felt good since I had to think like a coach, like about players how they feel, how, if they are comfortable." And, in the end of project survey response to "What worked well in this program?", Sofia responded "What it work [sic] well for me is by practice our character about sports coach." Both participants noted that they learned to share ideas and come to agreement with one another through creating the proposal together in character. In the focus group, after the fourth session where the participants worked extensively as their coach characters on building their Sports Club proposal, Sofia said that "What I learned in today's session is that we could agree with each other about a project for sports and clubs," and Natsu reflected that "What I saw is that everybody was communicating and I think, um, I was having fun." A significant moment also occurred in the fourth workshop when the participants as their coach characters decided on how they wanted to advertise for the new Sports Club program. Sofia suggested that we advertise in multiple languages, such as Spanish. Natsu agreed that this was a good idea, and added that we could include other languages as well such as Swahili and "languages from India."

My findings on process drama, Mantle of the Expert, and the ensemble-building techniques I used with the Choice Learning group support Cummins' (2000) and Paris and Alim's (2014) emphasis on pedagogy that recognizes students' identities, and linguistic and cultural backgrounds. Moreover, process drama enabled a "community of practice," "teaching through conversation," and "cooperative learning" to occur, exemplifying García and Kleifgen's argument for creative and collaborative learning for emergent bilinguals (2018, pp. 112-114). Deciding on the topic of "Sports Clubs" together and then providing a specific collaborative task of coming up with a proposal for a sports club program allowed for spontaneous verbal interaction in English, and it fostered participant enjoyment through 
creatively sharing and cooperating throughout the session, thus, in turn, encouraging further communication in the target language. Games and story-sharing within the overall performative method offered a space for students to assert aspects of their linguistic and cultural experiences. More significantly, Mantle of the Expert provided participants with the opportunity to contribute their ideas on the importance of language diversity, stemming from their own experience and identity as emergent bilingual students.

On the other hand, with the Valencia group, I found that process drama and Mantle of the Expert did not work as well to foster verbal communication and perspective sharing in the target language. In a larger group with varied language levels and first languages, I needed more time to not only explore different options for the topic, but also to successfully scaffold drama terms and concepts according to language ability prior to choosing and introducing the task for the drama. Moreover, I noticed confusion amongst participants during the session when I asked the group to think of themselves in-character as professional dancers. Though I intended for students to envision themselves as a new character, participants drew on characters from books or movies that they had previously mentioned during a warm-up activity. I discovered that, when using a method such as process drama that relies on sustained communication in-character within the dramatic world, I needed to more effectively build in character work with this group so that they fully understood the task as well as had the language skills to develop a persona and communicate as that character.

However, in both of the above scenarios, while I gave students the option to choose the topic, I decided on the structure for the process drama, giving students a pre-determined framework to work within, for example, designing a Sports Club program for the city of Phoenix. Particularly with the Valencia group, where I needed more time to effectively build into the drama, the students had limited ability to participate as characters who decided how the sessions unfolded. Even at Choice Learning academy where the group did decide on how they wanted to develop their proposal for the Sports Club program, I did not give my participants the opportunity to develop the overall dramatic framework itself, nor did I give them choice in the data collection methods. Here, I could have more effectively considered how I was working to not only incorporate the cultural and linguistic perspectives of my participants, but the extent of their decision-making power as well, if my ultimate goal was to situate the groups as collaborators in the inquiry process.

\section{Discussion}

Cañas (2015) argues that artists must examine how their methodology promotes equitable exchange, and how participation frameworks situate power. Although I intended to offer students the ability to participate using multiple forms of communication, and to draw on 
their first languages in the data collection from the focus-groups and surveys, this did not guarantee that the students felt supported enough to do so. The preceding point raises questions as to how effectively I opened the space to equitable language exchange, where students had the resources to contribute using their first languages. While I reflected that Mantle of the Expert did successfully position students as decision-makers in the space within the dramatic scenario that I created, my methods ultimately offered limited opportunities for students to drive the sessions as a whole. Positioning students as experts was not a "foolproof methodology," in Cañas' (2015) words, for shifting the power to the students as I had hoped to do. Process drama encouraged participants to share their perspectives, but I also needed to further examine how I was asking for and offering participation from students with differing language levels. I realized that while I chose process drama and Mantle of the Expert as a technique to support students' voice, agency, and cultural expression in the space, I also needed to ensure that I met their language capabilities and that I provided differing avenues of participation for students within my approach in order to further incorporate them into the decision-making processes.

In reflecting on the preceding observations regarding choice, decision-making, and expression of language, I offer two key points in regards to what drama practitioners and language teachers can consider when working with performative methods of language teaching informed from a critical intercultural perspective. Based on my data analysis and findings, I provide questions to serve as a guide to educators in the field of both drama and bilingual education, and state how they connect to Cañas' points in her manifesto:

- Participation that positions students as decision-makers and collaborators: How do/does the method(s) incorporate students as the collaborators not only within the dramatic framework, but within their participation in the class as a whole? Although I chose a methodology and methods of teaching that I thought would include students in my inquiry and provide space for diverse linguistic and cultural expression, the participants' collaboration in the process was more limited than I intended. Cañas (2015) discusses how projects can either challenge existing power structures, or maintain them. In a language classroom, where the power so often lies with the teacher, how do the drama methods act as an intervention to shift power and decision-making to the students?

- Equitable engagement in students' first language: How do/does the method (s) open a space for students to engage in their first languages? Cañas (2015) asserts that artists must pay careful attention to the exchanges in the collaboration process. Students' first languages need to be recognized, but more importantly, when given the opportunity to use another language, students need to be heard and understood, and provided equal support in doing so. When my participants knew that they were able to use and ask for support in their first languages, they felt their home languages 
valued, and expressed positive feelings towards the sessions. In a language class, how do the drama methods create linguistic exchanges that not only foster communication in the target language but support students in accessing their first languages when needed?

\section{Conclusion and moving forward}

I now reflect on where to take this work next, both for the field of performative language teaching and for myself as a drama practitioner and language educator. I offer a few suggestions in regards to directions for future studies employing inquiry-based performative methods. Future studies can benefit from attention to how performative methods meaningfully integrate students' use of their first languages, while also scaffolding interaction in the target language. Furthermore, although my project used tenets of YPAR, my model did not truly engage students in developing the methods of data collection or incorporate their perspectives into the analysis process. Thus, the field of performative language teaching can benefit from further long-term inquiries that use YPAR as the research framework and work with emergent bilingual students to decide on the topic, assessment, data collection, and data analysis methods.

Although my approach focused on culturally sustaining and ethical research practice with language minoritized youth, best intentions did not necessarily guarantee best practice. Following Cañas' manifesto means that at every stage in the partnership process, drama practitioners and artists must question their intentions and reflect on how power dynamics operate in spaces when working with refugees and asylum seekers. Similarly, in the context of language learning, where teaching has been fraught with inequity and deficit-based views of English language learners, drama practitioners and language teachers must critically reflect on how they are working to include the cultural and linguistic knowledge of their students. I discovered through my own project that this critical reflection applies not only to the research framework, but to the entirety of the collaboration and the performative methods I used. I learned that it was just as important to reflect on what I saw happening in the workshops amongst my students as it was to reflect on myself as a teacher. In ethical practice with emergent bilinguals, reflection in and on praxis will serve as key to ensuring that we center and honor the multiple languages, cultures, and realities of emergent bilingual youth. 
Nilson: Drama and critical intercultural language pedagogy

Bibliography

Cammarota, J., \& Fine, M. (2008). Revolutionizing education: Youth participatory action research in motion. Routledge. ProQuest.

Cañas, T. (2015, October 5). 10 things you need to consider if you are artist not of the refugee and asylum seeker community- looking to work with our community. Rise.

https://www.riserefugee.org/10-things-you-need-to-consider-if-you-are-an-artist-not-of-therefugee-and-asylum-seeker-community-looking-to-work-with-our-community/

Cummins, J. (2000). Language, power and pedagogy: Bilingual children in the crossfire. Language, power and pedagogy. Multilingual Matters. ProQuest.

Frimberger, K. (2017). The ethics of performative approaches in intercultural education. In J. Crutchfield \& M. Schewe (Eds.), Going performative in intercultural education: International contexts, theoretical perspectives and models of practice languages (pp. 44-63). Multilingual Matters.

García, O., \& Kleifgen, J.A. (2018). Educating emergent bilinguals: Policies, programs, and practices for english learners ( 2 nd ed.). Teachers College Press.

Greatschools.org (n.d.). Alhambra elementary district. https://www.greatschools.org/arizona/phoenix/alhambra-elementary-district/

Heathcote, D., \& Bolton, G. (1995). Drama for learning: Dorothy Heathcote's mantle of the expert approach to education. Heinemann.

Kao, S., \& O'Neill, C. (1998). Words into worlds: Learning a second language through process drama. Contemporary studies in second language learning. Ablex.

Liddicoat, A.J., \& Scarino, A. (2013). Intercultural language teaching and learning. Wiley-Blackwell. ProQuest. https://doi.org/10.1002/9781118482070

Mantle of the Expert. (n.d.). How can MoE be used? https://www.mantleoftheexpert.com/what-ismoe/how-can-moe-be-used/

Mantle of the expert. (n.d.). The New Zealand curriculum online. https://nzcurriculum.tki.org.nz/Archives/Media-gallery-archive/2011/Mantle-of-the-expert

Neelands, J., \& Goode, T. (2000). Structuring drama work: A handbook of available forms in theatre and drama. Cambridge University Press.

Paris, D., \& Alim, H. S. (2014). What are we seeking to sustain through culturally sustaining pedagogy? A loving critique forward. Harvard educational review, 84(1), 85-101. https://doi.org/10.17763/haer.84.1.9821873k2ht16m77

Phipps, A. (2013). Intercultural ethics: Questions of methods in language and intercultural communication. Language and intercultural communication, 13(1), 10-26.

https://doi.org/10.1080/14708477.2012.748787

Piazzoli, E. (2010). Process drama and intercultural language learning: An experience of contemporary italy. RiDE, 15(3), 385-402. https://doi.org/10.1080/13569783.2010.495272 
Nilson: Drama and critical intercultural language pedagogy

Piazzoli, E. (2011). Process drama: The use of affective space to reduce language anxiety in the additional language learning classroom. Research in drama education, 16(4), 557-573. https://doi.org/10.1080/13569783.2011.617104

Rothwell, J. (2011). Bodies and language: Process drama and intercultural language learning in a beginner language classroom. RiDE, 16(4), 575-594. https://doi.org/ $\underline{10.1080 / 13569783.2011 .617106}$

Saldaña, J. (2015). The coding manual for qualitative researchers (3rd ed.) Sage University Press.

Salopelto, H. (2008). Intercultural competence through drama: A teaching experiment. Department of Languages University of Jyväskylä.

Shin, S. J. (2018). Bilingualism in schools and society: Language, identity, and policy (2nd ed.). Routledge, Taylor \& Francis Group. 